\title{
Bilateral Optic Nerve Meningioma
}

National Cancer Institute

\section{Source}

National Cancer Institute. Bilateral Optic Nerve Meningioma. NCI Thesaurus. Code C5304.

Meningiomas that affects both optic nerves. 